\title{
Technology management routines that matter to technology managers
}

\section{Daniel Z. Levin*}

Management and Global Business Department, Rutgers Business School - Newark and New Brunswick, Rutgers University, 111 Washington Street, Newark, NJ 07102, USA Fax: (973) 353-1664 E-mail: levin@business.rutgers.edu *Corresponding author

\section{Helena Barnard}

Gordon Institute of Business Science, University of Pretoria, 26 Melville Road, Illovo, Sandton, 2191 South Africa Fax: 27 (11) 771-4177 E-mail: barnardh@gibs.co.za

\begin{abstract}
This study addresses the fragmentation in the technology management field by identifying and organising the routines used by managers of technology. In a multi-method, iterative qualitative study done jointly between academics and technology managers from a number of large industrial firms, 27 technology management routines were identified. These 27 routines were organised into a framework consisting of four categories: producing scientific and technological knowledge, transforming knowledge into working artefacts, linking artefacts with user requirements, and providing organisational support. This framework provides an organising scheme to make sense of technology management routines. In addition, because managers of technology actively participated in developing the routines, the study contributes by identifying routines practitioners regard as particularly important. Both research and practical implications are derived from the framework.
\end{abstract}

Keywords: process; routine; technology management framework.

Reference to this paper should be made as follows: Levin, D.Z. and Barnard, H. (2008) 'Technology management routines that matter to technology managers', Int. J. Technology Management, Vol. 41, Nos. 1/2, pp.22-37.

Biographical notes: Dr Daniel Z. Levin is an Associate Professor at Rutgers University in the Rutgers Business School - Newark and New Brunswick. $\mathrm{He}$ received his $\mathrm{PhD}$ at Northwestern University's Kellogg Graduate School of Management. His research focuses on organisational learning and knowledge transfer, including the role of social networks, routines, and trust. An active researcher and teacher, he has won Rutgers Business School's junior faculty research award and also the school's junior faculty teaching award.

Dr Helena Barnard completed her PhD in International Business at Rutgers University. Her research interests lie at the intersection between international business, innovation, and industrial upgrading. She carries out research on how firms conceptualise innovation and technology management and how they innovate, both consciously and in the course of day-to-day business. 


\section{Introduction}

Technology and technology development are critical to the health and survival of modern organisations and provide firms with an enormous economic multiplier effect (Roussel et al., 1991). The management of technology requires the integration of multiple activities from different parts of the organisation, a task with which many corporations struggle, especially in the face of increasingly high-velocity environments. Research and development (R\&D) groups, for example, often have strained or problematic relationships with other parts of the organisation: Perceptions that business units (and their customers) do not want enough of the technologies that R\&D develops are as likely to occur as are perceptions that $R \& D$ does not develop enough of the technologies that business units do want. In addition, complaints about the expense and time needed for technology transfer and the poor communication between business units and R\&D are typical.

In dealing with these problems, however, practitioners feel that the literature on the management of technology is too sparse and fragmented and does not adequately address their concerns, issues, and problems (Levin et al., 1997; National Center for Manufacturing Sciences, 1996). For example, there is a general sense in the literature itself that the many detailed mathematical models of project selection are rarely, if ever, practical (Baker and Pound, 1964; Carbno, 1999; Jones and Twiss, 1978). Moreover, 'the literature on the management of technology is a fragmented one, and one largely lacking in an overarching framework.' (Levin et al., 1997)

In a joint study between academics at two US research universities and a group of a half-dozen major US companies (under the auspices of the National Center for Manufacturing Sciences), a literature review ${ }^{1}$ confirmed the impression of these practitioners and the findings of Shenhar and Gaynor (1996) that the literature in this area is fragmented and incomplete. To begin integrating these various aspects of technology management into a useful and systematic framework, this joint academic-practitioner partnership began a study to identify the routines that the technology managers of large organisations actually use.

The current paper describes the results of this study and provides a framework of technology management routines that is analytically rigorous for scholars while practical and helpful for practitioners. From a theoretical perspective, the study is situated within a resource-based view of the firm (Collis, 1994; Grant, 1996; Levitt and March, 1988), where the firm's ability to manage the creation and application of technology is regarded as central to a firm's long-term success. By foregrounding the routines through which technology is managed, the potential and importance of organisational learning is also recognised. Of course a major difficulty in trying to increase organisational learning in the technology management domain is the sheer complexity of this domain (Cohen and Levinthal, 1990). By methodically and comprehensively identifying and organising the organisational routines in the technology management domain, this paper develops a new way to see the technology management 'landscape'. This work thus complements more traditional approaches - such as those focusing on organisational types, characteristics, and structures (Tidd et al., 2005) - by providing researchers and managers with a new lens of analysis in the technology management domain. 


\section{Routines in technology management}

The current study focuses on routines (i.e. on what practitioners often call processes) in the technology management domain of large corporations. Organisational routines are defined as 'the regular and predictable behavioural patterns within firms that are coping with a world of complexity and continuous change' (Pavitt, 2002, p.117), or stated differently, 'as a coordinated, repetitive set of organizational activities' (Miner, 1991, p.773). Traditionally, in the study of technology management, either the individual, the group, or the organisation is used as the unit of analysis (Roberts et al., 1978). What this paper proposes is that the routine also be used as a unit of analysis. By focusing on routines, the emphasis is not so much on the actors per se but on their activities. Routines are often seen as the building blocks of organisational learning and knowledge management (Levitt and March, 1988; Miner, 1990), and this study looks at organisational routines and interprets them as firm capabilities that evolved in response to technology management requirements.

There is, however, a controversy over how it is that routines can be repeated and predictable on the one hand, yet on the other hand still facilitate change and innovation. This inherent tension was recently addressed by Zollo and Winter (2002), who argue that routines can be designed specifically to enhance innovation and thereby form the basis for dynamic capabilities. This argument is consistent with earlier work (Teece et al., 1997) that distinguished dynamic capabilities from more static resources as a source of competitive advantage, with routines forming the basis for these dynamic capabilities. These theoretical approaches to innovation-related routines, however, have rarely been examined empirically. One exception has been an empirical study of the routines involved in technology brokering (Hargadon and Sutton, 1997). In the current paper, we focus more broadly on identifying and describing all the major technology management routines used by large firms.

From a technology management perspective, the result is a framework that:

- better connects strategic (macro) and project (micro) levels of analysis

(Burgelman, 1983)

- better understands the terminology, jargon, and thought patterns (i.e. the "cognitive categories') that people use to describe technology management and how work gets done

- better connects to the increasingly important resource-based view that specialised knowledge and routines are one of the few, if not only, sources of sustainable strategic advantage (Collis, 1994; Grant, 1996; Levitt and March, 1988)

- better translates rigorous research into findings useful to practitioners, a goal endorsed by leading academic scholars (Hambrick, 1994; Mowday, 1997).

Because the routines in this study were jointly formulated by managers of technology, their perspectives and preoccupations have shaped how the routines are defined. Some routines are presented in general terms ('provide post-project support'), while others are more thoroughly delineated (e.g. five different kinds of strategy-formulation routines). It is certainly possible that other actors in the creation and dissemination of new technology - for example, scientists or new product development teams - might identify, or at least emphasise, different routines. However, we argue that this potential 
variance is meaningful. Since the participants - who are managers of technology, not technologists - described the routines that they were more concerned about in great detail, the framework of routines in this paper does not provide a neutral rendering of all the technology management routines that can be - or need to be - found in firms. Rather, it provides a map of those routines that matter most from the perspective of the people charged with managing their firm's technological resources.

Our contribution, then, is to clarify and identify which are the routines that facilitate technology management and innovation in firms; i.e. routines that can be the basis for dynamic capabilities (Teece et al., 1997; Zollo and Winter, 2002). In addition, we categorise these routines in a way that is consistent with the literature on innovation, especially incremental and architectural innovation (Tushman and Smith, 2002). Later, in Section 5, we consider the limits and consequences that our focus on technology managers has for how firms deal with discontinuous innovation.

\section{Methodology}

The origin of this study occurred when a group of manufacturing-oriented companies approached a major US research university to ask for help in better understanding and dealing with the management of technology, as they had found the technology management literature fragmented and unhelpful. The practitioner group consisted of representatives from six large manufacturing-oriented firms (e.g. in industrial products, consumer goods), mostly senior technology or engineering managers whose jobs focused primarily on business-related issues. The academics consisted of several professors and $\mathrm{PhD}$ students, in both the business school and engineering school at two US research universities. The joint team was charged with documenting the state of the literature in this field and with developing a new framework that would encompass much of the academic research up to that point and also be firmly rooted in practitioner concerns. Three sources of data - a literature review, field visits, and working sessions with technology managers from participating companies - were used iteratively to develop this framework (Eisenhardt, 1989; Glaser and Strauss, 1967). The process was documented in the minutes of meetings, in e-mail exchanges among participants, and in participants' presentations and critiques of draft frameworks.

The academic team started developing a literature review in response to the practitioner request, beginning with Adler's (1989) extensive review of the technology management literature and working backwards and forwards in time from there. The team worked backwards in time by using many of Adler's categories and identifications of the key existing research. The team worked forwards in time by noting which journals were most cited in Adler's comprehensive bibliography, and then combing through those journals ${ }^{2}$ in addition to several organisational journals ${ }^{3}$ and miscellaneous other relevant articles, books and recent $\mathrm{PhD}$ dissertations. In all, the academic team identified 441 texts (mostly articles). All of this literature was categorised and re-categorised, as the overall framework emerged.

The literature review was distributed among practitioners for comments, and was also used to identify core issues for the field visits and working sessions. The field visits consisted of interviews with two dozen managers and engineers at various hierarchical levels in the corporate staff functions, business units, and R\&D labs of two different 
large companies participating in the project. The interviews were largely open-ended, but centred on the routines and issues facing the interviewees in their daily work. The team also examined and analysed company documents, specifically organisation charts and attempts to routinise technology management; e.g. flowcharts and forms required for different stages.

Thirdly, in parallel with the literature review and the fieldwork, was a series of joint working sessions with practitioners over a period of several months. During these sessions - conducted mostly in person but sometimes by conference call - the academic/practitioner team discussed what, in the experiences of practitioners, were the main technology management routines, using some of the literature and fieldwork findings as an initial baseline. An important advantage to using a Delphi-type technique, rather than just literature and fieldwork, is that it allows cross-company interaction among participants. This ensures that routines are actually widely enacted, although it does result in a loss of firm-specific detail due to competitive and proprietary concerns.

The approach to data gathering in this research represents somewhat of a departure from most qualitative research, which tends to involve the researcher generalising from the activities of practitioners. In this case, practitioners were themselves engaging in the literature, analysing practices, generalising, and generating conclusions. Academics acted mainly as facilitators, identifying and sharing literature, suggesting terminology if a suitable term existed, and documenting the process. In our view, it has been of great benefit to have key participants from participating firms provide critiques and refinements to the routines-based framework as it emerged.

Throughout the data gathering process, descriptions of technology management routines were disseminated among all project participants for discussion. Then, practitioners and academics alike considered questions such as: does this routine really operate as described? What other routines does it link to? What routines are missing from this list? The team looked for cross-firm commonalities in the technology management domain, focusing on generic routines and their interrelationships. Some firms used different names for the same routine, and depending on the firm, routines were sometimes formalised, and sometimes not. The emphasis, however, was on the existence of a repeated set of related activities in this domain, regardless of degree of formalisation or name. A routine was only included if all participants reached consensus that it represented a valid unit of related activities; this necessitated extensive dialogue and debate. After several iterations of literature review, field interviews, and joint analysis meetings, an overall framework of 27 generic technology management routines emerged.

In parallel with the identification of routines, there was a process of categorisation. A division derived from Adler (1989) was used as a starting point and refined based on dominant themes in the literature as well as a 'reality check' by practitioners. At the same time, and in accordance with the process of grounded theory building (Strauss and Corbin, 1998), clusters of routines emerged from the working sessions. An iterative process was followed to link these clusters into an overarching framework: the academic/practitioner team discussed proposed schemes of categorisation, and adjusted their categorisations. This process proved to be very difficult, which, given that the study was spurred by a concern with the fragmentation in the field, is hardly surprising.

The difficulties encountered by participants reflect that there is indeed not yet a consensus framework for how technology management routines interrelate. Participants found it fairly easy to agree on the specific routines involved, and could also identify 
sub-groups of routines. However, they struggled to generate an overarching framework. In each case, participants encountered difficulty when attempting to apply existing schemas of organisation in businesses to the management of technology. They used the corporate versus business unit versus R\&D distinction, experimented with project management and value chain principles, and settled on a (less than satisfying) strategic-, portfolio-, and product-level categorisation. Feeling that a more appropriate schema would be based on similarities in terms of the routines themselves, rather than where those routines are situated, the researchers revisited participant inputs and the literature, and revised the organising scheme. Thus the ultimate categorisation of the 27 routines represents the input of academics, but practitioners have generated the definition and content of each routine.

To limit repetition, the discussion of the organising scheme and the routines that constitute each dimension in the scheme will be discussed together.

\section{Results}

The development of new technology is a non-linear iterative process (Angle and Van de Ven, 1989). Successful innovative companies manage technology so that they are able to combine their knowledge of the requirements of customers - who are we servicing and what do they want? - with the company's (expanding) technological capabilities (Dougherty et al., 2000). Any framework for technology management routines must therefore accommodate both the expansion of technological capability and the determination of customer requirements. While Tushman and Smith (2002) do discuss both technology and market aspects of innovation, their framework concentrates on types of innovation (incremental, architectural, discontinuous) but not the actual activities of innovation, as captured by a focus on routines. Similarly, Tidd et al. (2005) focus their framework on organisational design characteristics of innovation (e.g. degree of centralisation, creative climate), but not the actual routines used in the technology management domain. Thus, in choosing a framework that would be consistent with these other perspectives on innovation - yet still describe the more detailed world of innovation-related routines - we were drawn to the work of Pavitt (2002).

Pavitt (2002) has suggested dividing innovation into three partially overlapping dimensions:

- producing scientific and technological knowledge

- transforming knowledge into working artefacts, reflecting that technological or scientific possibility does not necessarily imply practical feasibility

- matching artefacts with user requirements, whether internal (e.g. in the case of process innovation) or external (where the goal is new product innovation).

Since Pavitt's framework suggests the importance of both the user and the knowledge base, it presents a useful framework for categorising technology management routines. However, we identified one additional category - organisational support routines - that cuts across the three other categories. In fact, to the extent that these four broad categories in themselves constitute repeated, coordinated sets of activities, they can be seen as 'master' routines. 
Figure 1 Framework of technology management routines

\begin{tabular}{|c|c|c|}
\hline $\begin{array}{l}\text { Producing scientific and } \\
\text { technological knowledge }\end{array}$ & & $\begin{array}{l}\text { Matching artefacts with user } \\
\text { requirements }\end{array}$ \\
\hline $\begin{array}{l}\text { a) Ideation ('creative } \\
\text { process' to develop } \\
\text { new product/process) } \\
\text { b) R\&D environmental } \\
\text { monitoring (scan and } \\
\text { analyse the external } \\
\text { environment, } \\
\text { especially technology) } \\
\text { c) R\&D technology } \\
\text { strategy (plan } \\
\text { progression of } \\
\text { technology to be } \\
\text { developed by R\&D) } \\
\text { d) R\&D portfolio } \\
\text { management (evaluate } \\
\text { portfolio of R\&D } \\
\text { projects to achieve } \\
\text { desired balance along } \\
\text { different dimensions) } \\
\text { e) Intellectual property } \\
\text { management (manage } \\
\text { patents, copyright, } \\
\text { trademarks, standards) } \\
\text { f) Post-project audit } \\
\text { (discuss and } \\
\text { disseminate lessons } \\
\text { learned) }\end{array}$ & $\begin{array}{l}\text { Transforming knowledge } \\
\text { into working artefacts } \\
\text { g) Technology roadmapping } \\
\text { (develop a plan for what } \\
\text { technologies will be } \\
\text { needed to support a given } \\
\text { product/process in the } \\
\text { future) } \\
\text { h) Product line planning } \\
\text { (develop a plan for future } \\
\text { direction of product } \\
\text { line/platform) } \\
\text { i) Product portfolio } \\
\text { management (evaluate } \\
\text { portfolio of products to } \\
\text { achieve balance along } \\
\text { dimensions) } \\
\text { j) Feasibility (investigate } \\
\text { the market and technical } \\
\text { feasibility of an idea) } \\
\text { k) Project execution } \\
\text { (planning, designing, } \\
\text { staffing, and managing - } \\
\text { the 'actual work' - of a } \\
\text { project) } \\
\text { 1) Technology transfer } \\
\text { (shift ownership of } \\
\text { artefact and } \\
\text { accompanying } \\
\text { knowledge) } \\
\text { m) Technology adaptation } \\
\text { (absorb and adapt a } \\
\text { technical artefact and } \\
\text { accompanying } \\
\text { knowledge) } \\
\text { n) Post-project support } \\
\text { (provide support to } \\
\text { adopters of technology) }\end{array}$ & $\begin{array}{l}\text { o) Business unit environmental } \\
\text { monitoring (scan and analyse } \\
\text { competitors, suppliers, } \\
\text { customers, technologies, } \\
\text { regulators, etc.) } \\
\text { p) Corporate environmental } \\
\text { monitoring (scan and analyse } \\
\text { competitors, suppliers, } \\
\text { customers, technologies, } \\
\text { regulators, etc.) } \\
\text { q) Business unit business strategy } \\
\text { (develop business unit's plan } \\
\text { and budget) } \\
\text { r) Corporate business strategy } \\
\text { (develop company's overall } \\
\text { plan and budget) } \\
\text { s) Technology needs assessment } \\
\text { (determine what technologies } \\
\text { current and future customers } \\
\text { want) } \\
\text { t) Business unit technology } \\
\text { strategy (determine the role of } \\
\text { various technologies in a } \\
\text { business unit) } \\
\text { u) Corporate technology strategy } \\
\text { (determine role of R\&D and } \\
\text { technology in company) } \\
\text { v) Initial programme/project } \\
\text { selection (determine if a } \\
\text { programme/project should be } \\
\text { funded) } \\
\text { w) R\&D funding (determine how } \\
\text { to fund R\&D efforts) } \\
\text { x) New business unit } \\
\text { development (determine when } \\
\text { a new set of products/ } \\
\text { technologies/markets warrant } \\
\text { the formation of a new } \\
\text { business unit) } \\
\text { a }\end{array}$ \\
\hline \multicolumn{3}{|c|}{ Providing organisational support } \\
\hline $\begin{array}{l}\text { y) Performance manager } \\
\text { z) Personnel managemer } \\
\text { aa)Technology alliance } n \\
\text { consortia) }\end{array}$ & $\begin{array}{l}\text { measure and manage perf } \\
\text { e and develop skilled pers } \\
\text { sement (identify, develop }\end{array}$ & $\begin{array}{l}\text { nce) } \\
\text { l) }\end{array}$ \\
\hline
\end{tabular}


The graphic representation of the framework shown in Figure 1 is consistent with the notion that technology management routines do not operate in a linear sequence (Angle and Van de Ven, 1989); i.e. there is no single 'starting point' from which innovation originates. First, within each of the main categories of the framework, there is an iterative process of connection between different routines. In addition, we have noticed - in the literature as well as in this study's data gathering - that technologists tend to advocate a 'technology push' approach, where innovation moves from left to right in Figure 1; that marketers tend to advocate a 'market pull' approach, where innovation moves from right to left; and that technology managers tend to advocate an 'inside-out' approach, where innovation originates from the centre of Figure 1, at the confluence of technology- and market-oriented spheres, and then moves outward both to the left and right.

\subsection{Producing scientific and technological knowledge}

From the point of view of the manager of technology, the creation of new knowledge (the left-hand column in Figure 1) is a fairly opaque dimension, primarily the domain of scientists. 'Ideation', the creative process of developing a new idea or technical solution to a problem (routine A), is at the heart of new knowledge generation, and R\&D typically plays the greatest role in this routine. In the roundtable discussions, managers repeatedly identified the tension between providing a supportive framework or direction, and leaving space for creativity as central to this routine. Although the ideation process is supported by a variety of planning-related activities as well as by the management of existing knowledge assets, managing this tension is central to all the support routines.

We first discuss planning-related routines. Firm-specific production of scientific and technological knowledge takes place within the context of wider scientific advances, requiring the scanning of the external technological environment (routine B). One tension that has to be managed is the need to find points of connection between the business units (that tend to be sceptical of $R \& D$ ) and with $R \& D$, which is not always adequately sensitive to the more immediate concerns of the business units. Another difficulty with $\mathrm{R} \& \mathrm{D}$ environmental monitoring is the problem of managing a process that does not really have a concrete deliverable. In a sense, the most concrete deliverable for routine $\mathrm{B}$ is the formulation of a technology strategy, but formulating technology strategy in fact represents another distinct routine $(\mathrm{C})$ in which the firm defines the scientific and technological areas it wants to concentrate on, the time horizon and concreteness of technology plans, and how strong R\&D's educational role towards the rest of the company should be. This routine also shapes the firm's desired R\&D portfolio. R\&D portfolio management (routine D) enables the firm to evaluate and manage its portfolio of $R \& D$ projects to determine and plan for the desired balance among different technologies and scientific fields, and practitioners described it as the bridging routine between strategy and actual R\&D projects. However, because business units, R\&D and the corporate head office are all stakeholders in this integrative routine, and because of the difficulty in identifying objective dimensions to evaluate projects, the power of different organisational units often heavily influences the balance among R\&D projects. A range of practices, like evaluating all projects (quantitatively where possible), balancing incremental and radical innovations, and developing programmes of research (i.e. groups of related projects) are all important to ensure the integrity of this, in the words of the participants, 'fulcrum' routine. 
As for the management of existing assets, it has been demonstrated that firms' existing capabilities have a marked effect on the type of competencies firms develop in the future (Cantwell and Fai, 1999; Maskell and Malmberg, 1999). Management routines are therefore necessary whether these assets are codified for external parties, as in the case of intellectual property management (routine E), or the internal results of learning-by-doing, for example as captured through a post-project audit (routine F). Participants defined this latter routine as the analysis of root causes of both good and bad outcomes, with benchmarking as an important technique. For both intellectual property management and post-project routines, the emphasis is on the potential for organisational learning, i.e. on facilitating a common assessment of success (or failure) by all stakeholders.

\subsection{Matching artefacts with user requirements}

Like the production of scientific and technological knowledge, the matching of artefacts with user requirements (the right-hand column in Figure 1) requires the firm to orient itself relative to the external environment. But while knowledge-creation routines focus specifically on scientific and technological dimensions, the matching of artefacts with user requirements encompasses a wider range of routines, where the environment must be defined more broadly.

Large firms use routines for both environmental monitoring and strategy formation. Environmental monitoring at the business unit level (routine $\mathrm{O}$ ) involves 'bringing information about the external environment into the boundary of the organization' (Moorman, 1995, p.350) through the analysis of competitors, suppliers, customers, technologies, regulators and so on. This is similar at the corporate level (routine P), although the business unit routine has a particular focus on products and customers, with a fairly tight linkage to other business unit-level strategy routines, while corporate-level environmental monitoring routines are especially concerned with integrating observations from multiple business units. A key challenge for corporate environmental monitoring routines is the issue of how centralised the information gathering, consolidation and dissemination should be. Likewise, at the level of the business unit, the routine for formulating business strategies, which participants framed as the formulation of plans, sales forecasts, and budgets (routine Q), is keenly concerned with linkages and (de)centralisation, such as integrating the business unit's plans with corporate strategic requirements and with the plans of other business units. At the corporate level, business strategy formulation (routine R) again is concerned with the trade-off between centralisation and decentralisation. In particular, the corporate office has to define an overall vision and goals, but in such a way that it is in keeping with the organisation's structure and culture (e.g. whether a corporate strategy group can enforce strategy implementation or requires buy-in by business units).

Technology needs assessment (routine S) allows the business unit and R\&D to determine what technologies current and future customers want. In the case of incremental innovation, this routine is fairly straightforward if there is adequate communication between key units, especially R\&D and business units. However, in the case of radical innovation, the routine may have to be executed by $R \& D$ rather than a business unit - sometimes on behalf of a business unit that has yet to be established. This routine is therefore ideally supported by focused technology councils with managers from a range of different functions inside and perhaps even outside the organisation. 
This information on technology needs, in turn informs the technology strategy formulation routines. Technology strategy at the level of each business unit (routine T) and the corporation (routine U) represents the firm's technology response to user requirements. At the business unit level, it is a narrowly focused routine, with the emphasis on aligning the technology strategy with the business unit's goals. At the corporate level, the routine involves aspects such as how the firm pursues its technology acquisitions, its marketing programmes, technological areas of focus, and make/buy decisions. Although practitioners recognised the close interrelation among the different kinds of technology strategy routines, the R\&D-level technology strategy (routine C) is focused on the generation of capabilities, while technology strategy at the corporate and business-unit levels is more concerned with the exploitation of capabilities. Since technology strategy at the $R \& D$ level is shaped more by emerging opportunities in the science base than in relation to an explicit end user, it was categorised as a routine for producing new knowledge.

Innovation is mostly funded, either directly or indirectly, by users willing to pay for an improved process or new product. The most obvious example of this is initial programme/project selection (routine V), where new programmes and projects will only be funded if the expected benefits outweigh the costs. Participants described this routine as a centrepiece for technology management, guided by the portfolio goals (what the firm wants) and shaped by technology roadmapping (what the firm can do). Although recognising that project development does not proceed in a linear fashion, participants defined this routine as marking the 'official' beginning of a project's life. While the link with users is less direct for R\&D funding (routine W) - since some research may still be too exploratory to be linked to a specific artefact or user, or it may be possible to obtain public funds - participants' concern with overcoming the all-too-often marginal relevance of R\&D suggests that there are real dangers in separating funding from at least anticipated user needs. This routine therefore involves managing the level, frequency, and flexibility of funding so that both the need for stability and continuity in research efforts, and also responsiveness to business unit concerns, can be ensured. Determining when and how a new set of products, technologies, or markets warrant the formation of a new business unit (routine $\mathrm{X}$ ) is a deepening of the process of linking artefacts with user requirements, since the expansion of markets often leads to changes in the composition of users and their needs, as well as to changed technical requirements, e.g. as part of the transition to more mass-based manufacturing (Rosenberg, 1994). Participants pointed out that this routine prevents firms from focusing solely on the existing business units and their current products and customers bases, thereby allowing firms to accommodate more radical innovations. However, as this routine requires the firm to expand beyond its current boundaries, it needs to be coordinated with merger and acquisition activities and done in consultation with potentially affected existing business units.

\subsection{Transforming knowledge into working artefacts}

This category (the middle column in Figure 1) deals with routines that explicitly aim to connect user needs with the creation of new knowledge, and can be divided into planning-related and execution-related routines.

In terms of planning-related routines, technology roadmapping (routine $G$ ) emerged as one of the most important. Technology roadmapping is concerned with identifying 
and developing the technological capabilities needed to support a given product line or process in the future, and highlights where the technology will come from, how the business unit will get it, the major hurdles expected, and resources needed (Kappel, 2001). It is a bridging routine, and participants favoured doing it collaboratively between R\&D and business units, and using a somewhat standardised format to allow cross-unit comparisons. Product line planning (routine $\mathrm{H}$ ) serves to clarify the future direction of the firm's product lines or platforms by translating business drivers (e.g. cost, customer needs, competitive position) into product parameters. This routine is 'owned' by the business unit and provides a platform definition plan and timetable. Product portfolio management (routine I) requires the evaluation of products in terms of a range of measures that matter to business unit managers, such as sales, investment criteria, product platforms, and the choice of technologies. These different planning-related routines interrelate: the firm's assessment of its portfolio of products (routine I) feeds into product line planning (routine $\mathrm{H}$ ), which in turn connects with technology roadmapping (routine $\mathrm{G}$ ).

In addition to these planning-related routines, there are also several execution-related routines for transforming knowledge into working artefacts. Reflecting the fact that firms tend to use multifunctional teams in the management of technology (Griffin and Hauser, 1992), the execution-related routines relate strongly to project management activities. Doing feasibility studies (routine J) is a typical first step, and involves both technical feasibility (done by R\&D) and business feasibility (done by business units). This routine often has to be repeated as an innovation project advances, not only because innovation is an iterative, non-linear process, but because too much detail in the initial phases can prematurely cut off good ideas, but significant detail is required before committing to a project. The planning, designing, staffing, and managing of activities are captured under the broad routine 'project execution' (routine K), which requires the integrated management of different projects' timelines and milestones. Participants pointed out that the central challenge in successfully executing this routine is that $R \& D$ projects typically are more uncertain and take longer than business unit projects. Because R\&D projects take longer to execute, changes in corporate strategy may result in $R \& D$ projects that are no longer needed, and even if they are, the uncertainty of R\&D outcome dates may present business units with significant challenges.

Executing a transformation of knowledge into working artefacts also involves the dissemination of the new technology. Firstly, ownership of the artefact and its accompanying knowledge must be transferred from the unit where it was developed, typically $\mathrm{R} \& \mathrm{D}$, to other units (routine $\mathrm{L}$ ). This can be achieved through a range of strategies - delivering a prototype, training business unit personnel, temporarily transferring R\&D personnel, etc. Participants talked about 'an umbilical cord' that links R\&D to a project, and the difficulties R\&D often has of letting go. The mirror-routine is technology adoption, as the receiving units need to absorb and adapt (Leonard-Barton and Sinha, 1993) the artefact and accompanying knowledge (routine M). Participants pointed out the active role of the technology adopting unit and emphasised the need to prepare for the new technology, such as by developing new skills, practices, or distribution channels. For both routines $\mathrm{L}$ and $\mathrm{M}$, practitioners regarded partnership between the business unit and R\&D to be essential, and they recommended having business unit employees involved in the R\&D process, as well as ensuring that $\mathrm{R} \& \mathrm{D}$ employees are involved in the business unit-level technology adoption process. Thirdly, since the integration of the new knowledge is not a once-off event, 'post-project 
support' (routine N) was often requested by adopters of technology. Participants emphasised that this should be considered a routine activity, and not regarded as ad-hoc problem solving, since the need for sharing knowledge, resolving questions, and providing additional help is a predictable part of technology management.

It is telling that the participants did not break down the different elements of project execution into separate routines, whereas they did separate out three distinct routines related to technology transfer. This suggests the relative importance they assigned to these different routines. That is, technology managers seemed to give a higher priority to the spread of technological artefacts and the knowledge associated with them across the boundaries in the organisation than to tasks that take place within the boundaries of a single project. Similarly, Rosenkopf and Nerkar (2001) point out the importance of boundary crossing for successful innovation, and so the emphasis that technology managers place on boundary-crossing routines suggests that they, too, recognise its importance.

\subsection{Providing organisational support}

Organisational support routines cut across all three knowledge-related categories and have to do with the general managerial capabilities that enable the development and exploitation of new technologies. Performance management (routine Y) concerns the measurement and management of performance and the development of appropriate incentive schemes. This routine not only affects all three knowledge-related categories, but in fact has to reconcile their different performance management requirements. For example, a practical incentive scheme rewards both the matching of artefacts with user requirements - where it is possible to identify specific revenue (or cost-saving) streams - as well as the process of knowledge creation, which typically has longer timelines and less direct links with the end-user. Another support routine is personnel management (routine Z), concerned with hiring, developing, and retaining capable employees. This routine shares many similarities with typical human resource routines, but differs in a few important ways. Firstly, for scientists and engineers, intellectual freedom and contact with other researchers are particularly important and this has to be actively managed. A second consideration has to do with the ongoing tension between the creation of knowledge and its commercial application. Participants particularly mentioned the rotation of personnel to facilitate the spread of knowledge through the firm, and the option of dual career tracks as strategies to mitigate that tension. Like personnel management, the management of technological alliances (routine AA) aims to extend the capability of the firm to generate or exploit new knowledge. Participants emphasised that this routine is typically an output from strategy formation, and an input into the technological planning routines, cutting across all organisational units. Technological alliances can be organised around scientific research questions or new product development, and this routine involves identifying, developing, and managing the firm's strategic partnerships and consortia.

\section{Implications}

The 27 routines identified in this study provide a high-level view of what the generalist manager of technology needs to oversee. The routines are presented in a framework that 
cuts across functional boundaries (as technology management often requires) yet is intuitive enough to facilitate sensemaking by managers of technology. The four categories of the framework themselves represent 'master' routines, providing a clear but fluid organising schema for the fragmented field of technology management. In addition, the framework emphasises the non-linear nature of technology management. So a technology management sequence can be prompted by a new technological discovery (left to right in Figure 1), a newly defined user need (right to left in Figure 1), or attempts to combine known technologies with known user needs (an 'inside out' approach, starting in the centre and moving both left and right in Figure 1).

Although there are a number of articles that describe the functioning of specific technology management routines (e.g. Kappel, 2001), there has been as yet no attempt to describe comprehensively the routines found in this domain in large organisations. This article presents a cognitive map for identifying and making sense of these technology management routines. We list, describe, and organise the routines that technology managers of large firms identify as important in the management of technology, all within a comprehensive yet intuitive framework. This research thus provides a practical 'checklist' of the routines that technology managers agree must take place in order to manage technology effectively in a large firm, and provides practitioners with a point of comparison against which to measure their own routines.

To the extent that the framework can serve as a counterpoint to the fragmentation of the current literature, this study can benefit practitioners (including students wishing to become practitioners) and academics alike. For academics, this study provides a descriptive baseline of the technology management routines used in large corporations. This consensus map, then, can be used by academics to compare theories of innovation management, including future proposals of optimal engineering-management configurations, with actual work practices. This would allow academics to identify possible blind spots - both of practitioners and of researchers - and address them in future research.

Along these lines, we note that technology managers appear to be more focused on routines related to incremental and even architectural innovation (Tushman and Smith, 2002), but less so on managing discontinuous innovation. An open question, then, would be: is discontinuous innovation ever routinised, or is it - either in practice or by definition - a 'one-off' and rare phenomenon? One possibility is that the discontinuity of an innovation is a boundary condition for the framework of technology management routines presented here, which, in this view, would not apply to disruptive technologies. If this is in fact the case, then this would help explain why so many firms suffer from 'routine rigidity' (Gilbert, 2005), i.e. the finding that firms often fail to change organisational processes when circumstances change (Teece et al., 1997; Tushman and Anderson, 1986). That is, in contrast to the view that firms are unwilling to embrace discontinuous innovation because they are 'held hostage to their successful pasts' (Tushman and Smith, 2002, p.395), it could also be the case that firms are unable to introduce discontinuous innovation because they so rarely confront it and therefore have no routines for it. On the other hand, one could argue that technology management routines do in fact apply to discontinuous innovation. For instance, as noted in Section 4, several of the routines - e.g. R\&D portfolio management (routine D), technology needs assessment (routine $S$ ), new business unit development (routine $\mathrm{X}$ ) - do address the issue of radical innovation, according to 
the technology managers in our study. While discontinuous innovation is relatively rare (Rosenberg, 1982), it would nonetheless be helpful if future research could determine the extent to which this type of innovation is - or can be - routinised.

\section{Conclusion}

During this study's data gathering sessions, participating technology managers commented how helpful it was for them to be able to compare and contrast their technology management routines with those of other organisations. The academic field of technology management, struggling to come to terms with the increasing pace and extent of technological progress, can also benefit from hearing how practitioners make sense of their daily responsibilities. Practitioners in technology management are engaged in problem solving in their areas of expertise on an ongoing basis and therefore have the potential to offer valuable insights to scholars. This study complements existing research on technology management, where the insights of practitioners are often left unexamined, by foregrounding the voices of practitioners. In particular, this study offers a map of the technology management routines that technology managers regard as important, organised in a way that is consistent with the non-linearity of innovation. In so doing, it provides a benchmark of technology managers' practices that can inform future innovation management studies.

\section{Acknowledgements}

The authors wish to thank Fariborz Damanpour, George Farris, Abbie Griffin, Tom Kappel, Michael Radnor, Jeff Strauss, and Michel Thouati for advice and assistance with this research.

\section{References}

Adler, P.S. (1989) 'Technology strategy: a guide to the literature', in R.S. Rosenbloom (Ed) Research on Technological Innovation, Management and Policy, Vol. 4, Greenwich, CT: JAI Press, pp.25-151.

Angle, H.L. and Van de Ven, A.H. (1989) 'Suggestions for managing the innovation journey', in A.H. Van de Ven, H.L. Angle, and M.S. Poole (Eds) Research on the Management of Innovation: The Minnesota Studies, New York: Ballinger, pp.663-697.

Baker, N.R. and Pound, W.H. (1964) 'R and D project selection: where we stand', IEEE Transactions on Engineering Management, Vol. 11, No. 4, pp.124-134.

Burgelman, R.A. (1983) 'A process model of internal corporate venturing in the diversified major firm', Administrative Science Quarterly, Vol. 28, pp.223-244.

Cantwell, J. and Fai, F. (1999) 'Firms as the source of innovation and growth: the evolution of technological competence', Journal of Evolutionary Economics, Vol. 9, pp.331-366.

Carbno, C. (1999) 'Optimal resource allocation for projects', Project Management Journal, Vol. 30, No. 2, pp.22-31.

Cohen, W.M. and Levinthal, D.A. (1990) 'Absorptive capacity: a new perspective on learning and innovation', Administrative Science Quarterly, Vol. 35, pp.128-152. 
Collis, D.J. (1994) 'How valuable are organizational capabilities?' Strategic Management Journal, Vol. 15, Winter, pp.143-152.

Dougherty, D., Borreli, L., Munir, K. and O'Sullivan, A. (2000) 'Systems of organizational sensemaking for sustained innovation', Journal of Engineering and Technology Management, Vol. 17, pp.321-355.

Eisenhardt, K.M. (1989) 'Building theories from case study research', Academy of Management Review, Vol. 14, pp.532-550.

Gilbert, C.G. (2005) 'Unbundling the structure of inertia: resource versus routine rigidity', Academy of Management Journal, Vol. 48, pp.741-763.

Glaser, B.G. and Strauss, A.L. (1967) The Discovery of Grounded Theory: Strategies for Qualitative Research, New York: Aldine Publishing.

Grant, R.M. (1996) 'Prospering in dynamically-competitive environments: organizational capability as knowledge integration', Organization Science, Vol. 7, pp.375-387.

Griffin, A. and Hauser, J.R. (1992) 'Patterns of communication among marketing, engineering and manufacturing - a comparison between two new product teams', Management Science, Vol. 38, pp.360-373.

Hambrick, D.C. (1994) '1993 Presidential address: what if the Academy actually mattered?', Academy of Management Review, Vol. 19, pp.11-16.

Hargadon, A. and Sutton, R.I. (1997) 'Technology brokering and innovation in a product development firm', Administrative Science Quarterly, Vol. 42, pp.716-749.

Jones, H. and Twiss, B.C. (1978) Forecasting Technology for Planning Decisions, London: Macmillan.

Kappel, T.A. (2001) 'Perspectives on roadmaps: how organizations talk about the future', Journal of Product Innovation Management, Vol. 18, pp.39-50.

Leonard-Barton, D. and Sinha, D.K. (1993) 'Developer-user interaction and user satisfaction in internal technology transfer', Academy of Management Journal, Vol. 36, pp.1125-1139.

Levin, D.Z., Radnor, M. and Thouati, M.G. (1997) 'Using a process view of organizations to understand the management of technology', Paper presented at the Annual Meeting of the Academy of Management, Boston.

Levitt, B. and March, J.G. (1988) 'Organizational learning', Annual Review of Sociology, Vol. 14, pp.319-340.

Maskell, P. and Malmberg, A. (1999) 'Localised learning and industrial competitiveness', Cambridge Journal of Economics, Vol. 23, pp.167-185.

Miner, A.S. (1991) 'Organizational evolution and the social ecology of jobs', American Sociological Review, Vol. 56, pp.772-785.

Miner, A.S. (1990) 'Structural evolution through idiosyncratic jobs: the potential for unplanned learning', Organization Science, Vol. 1, pp.195-210.

Moorman, C. (1995) 'Organizational market information processes: cultural antecedents and new product outcomes', Journal of Marketing Research, Vol. 32, pp.318-335.

Mowday, R.T. (1997) '1996 Presidential address: reaffirming our scholarly values', Academy of Management Review, Vol. 22, pp.335-345.

National Center for Manufacturing Sciences (1996) Management of Technology: Feasibility Study, Ann Arbor, Mich.

Pavitt, K. (2002) 'Innovating routines in the business firm: what corporate tasks should they be accomplishing?', Industrial and Corporate Change, Vol. 11, pp.117-123.

Roberts, K.H., Hulin, C.L. and Rousseau, D.M. (1978) Developing an Interdisciplinary Science of Organizations, San Francisco: Jossey-Bass.

Rosenberg, N. (1982) 'Technological interdependence in the American economy', in Inside the Black Box: Technology and Economics, Cambridge: Cambridge University Press, pp.55-80. 
Rosenberg, N. (1994) Exploring the Black Box: Technology, Economics, and History, New York: Cambridge University Press.

Rosenkopf, L. and Nerkar, A. (2001) 'Beyond local search: boundary-spanning, exploration, and impact in the optical disk industry', Strategic Management Journal, Vol. 22, pp.287-306.

Roussel, P.A., Saad, K.N. and Erickson, T.J. (1991) Third Generation R\&D: Managing the Link to Corporate Strategy, Boston: Harvard Business School Press.

Shenhar, A.J. and Gaynor, G.H. (1996) 'Management of technology: definitions, boundaries, taxonomies, and scope', Paper presented at the Annual Meeting of the Academy of Management, Cincinnati.

Strauss, A. and Corbin, J. (1998) Basics of Qualitative Research: Techniques and Procedures for Developing Grounded Theory, London: Sage.

Teece, D.J., Pisano, G. and Shuen, A. (1997) 'Dynamic capabilities and strategic management', Strategic Management Journal, Vol. 18, pp.509-533.

Tidd, J., Bessant, J. and Pavitt., K. (2005) Managing Innovation: Integrating Technological, Market and Organizational Change, 3rd edn., Chichester, West Sussex, England: John Wiley and Sons.

Tushman, M.L. and Anderson, P. (1986) 'Technological discontinuities and organizational environments', Administrative Science Quarterly, Vol. 31, pp.439-465.

Tushman, M.L. and Smith, W. (2002) 'Organizational technology', in J. Baum (Ed) Companion to Organizations, Malden, MA: Blackwell, pp.386-414.

Zollo, M. and Winter, S.G. (2002) 'Deliberate learning and the evolution of dynamic capabilities', Organization Science, Vol. 13, pp.339-351.

\section{Notes}

The literature review is not included here due to space considerations, but is available on request.

2 These journals were: IEEE Transactions on Engineering Management, Management Science, $R \& D$ Management, and Research-Technology Management.

3 General organisational journals included Academy of Management Journal, Academy of Management Review, Administrative Science Quarterly, California Management Review, Harvard Business Review, Organization Science, Sloan Management Review, and Strategic Management Review. 